Article

\title{
How Well Do AR5 Sea Surface-Height Model Projections Match Observational Rates of Sea-Level Rise at the Regional Scale?
}

\author{
Phil J. Watson \\ School of Civil and Environmental Engineering, The University of New South Wales, Sydney, NSW 2052, \\ Australia; philwatson.slr@gmail.com
}

Received: 26 November 2017; Accepted: 24 January 2018; Published: 1 February 2018

\begin{abstract}
The reliance upon and importance of climate models continues to grow in line with strengthening evidence of a changing climate system and the necessity to provide credible projections for risk assessment to guide policy development, mitigation and adaptation responses. The utility of the models to project regional rates of sea-level rise over the course of the 21st century is reliant on evaluating model outputs against global observational data (principally altimetry products). This study compares rates of sea-level rise from observational data records (tide gauges) against the ensemble mean of the model-projection products used in AR5 at 19 sites around the world over the decade of common data coverage (2007-2016) using enhanced time-series analysis techniques. Although it could be concluded that the observational and model-projected average velocity agree ( $95 \%$ confidence level (CL)), error margins are comparatively wide, masking the fact that the mean velocity for the model-projection products exceed observational records for nearly all stations and Representative Concentration Pathway (RCP) experiments, and are likely in the range of 1.6-2.5 mm/year. The analysis might provide an early warning sign that the evaluation of ocean model components with respect to projected mean sea level could be relevantly improved.
\end{abstract}

Keywords: mean sea level; velocity; AR5 regional projection modelling

\section{Introduction}

Climate models are key tools in assisting in understanding and planning for the predicted impacts of a changing climate system. These models form central elements of the Assessment Reports of the Intergovernmental Panel on Climate Change (IPCC) [1,2] with great reliance placed on projection outputs to facilitate appropriate policy, adaptation and mitigation responses. By coordinating the design and distribution of global climate model simulations of the past, present, and future climate, the Coupled Model Intercomparison Project (CMIP) has become one of the foundational elements of climate science [3].

CMIP-Phase 5 (or CMIP5), provided an ensemble of climate models to support the IPCC's Assessment Report 5 (AR5) [2], each of which are required to meet established protocols including adherence to fundamental laws of nature and large-scale observational constraints across a range of physical parameters [4]. The relative sea surface-height (SSH) projection products used in AR5 [5] include the following 10 geophysical sources that drive long-term changes in relative SSH [6]:

- 5 ice components (Greenland dynamic ice and surface-mass balance, Antarctic dynamic ice and surface-mass balance, and glaciers);

- 3 ocean-related components, all of which are derived from CMIP5 models (dynamic SSH, global thermosteric SSH anomaly, and the inverse barometer effect from the atmosphere);

- land water storage (also called terrestrial water); and 
- glacial isostatic adjustment (GIA, as a change in sea level "relative" to land).

The next-generation models forming part of CMIP6 [3] have been under development since about 2012 to support the IPCC's Assessment Report 6 (AR6) [7], seeking amongst other things to capitalize on improving knowledge of complex integrated components of the climate system, enhanced computing power and outputs at increasingly finer resolution (or more localized scale).

In addition to advances in understanding and integrating key physical processes at an increasingly finer scale, improved projection outcomes from climate models are also critically reliant on better evaluation of modelling components against observational data. Recent literature has focused upon improving the regional resolution of SSH from CMIP5 by accounting for additional elements of the sea-level budget using improved offline modelled components and observation-based contributions [8]. Slangen et al. (2017) [9] provided an extensive evaluation of model simulations of 20th century sea level rise at the global scale compared to observational data from tide gauges and satellite altimetry spanning 1900-2015. This work made provision for sea-level contributions associated with groundwater depletion, reservoir storage, and dynamic ice-sheet mass changes that are not simulated by climate models.

A companion paper [10], provided a detailed evaluation of model performance at the regional scale by comparing these enhanced ensemble climate model outputs of SSH to tide gauge data (spanning the same period) at 27 sites around the world. The analysis concluded that for most of the tide gauge records, climate models tend to underestimate the observed twentieth-century trends. The analysis concluded the average difference between observed and modeled sea-level trends of the order of $0.27 \pm 0.77 \mathrm{~mm} /$ year $(90 \%$ confidence level $(\mathrm{CL})$ ) with discrepancies potentially explained by an underestimation in the uncertainty in Glacial Isostatic Adjustment (GIA).

These results are encouraging, suggesting agreement in sea-level trends between climate models and observational records at a regional level on a quasi-centennial timescale. This current analysis augments these previous works, taking a step further by comparing the AR5 SSH ensemble model projection products against a global network of tide gauges (refer Figure 1) for the period of overlapping coverage (2007-2016).

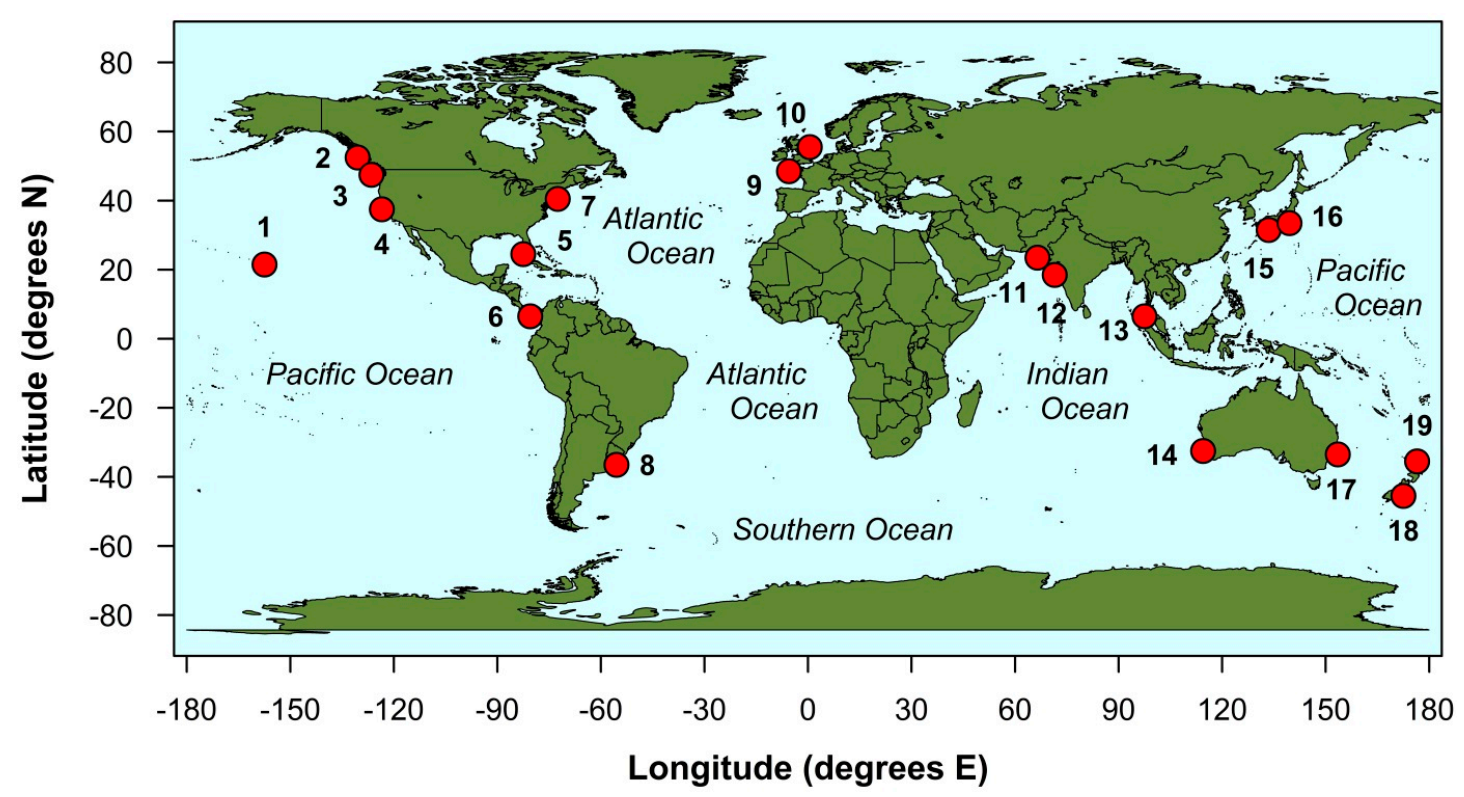

Figure 1. Location of analysis sites used in the study. Sites have been delineated with a station "ID" commencing with 1 (Honolulu, HI, USA) moving easterly to 19 (Auckland, New Zealand). Full details of data records are summarized in Table 1. 
The analysis is also enhanced by several key features that attempt to overcome ubiquitous issues associated with sea-level trend analysis. Firstly, the application of improved time-series analysis techniques, using singular spectrum analysis (SSA) enables separation of the inter-annual to multi-decadal variability from the external (or greenhouse-gas induced) forcing for both the SSH projection model ensembles and tide gauge records. The scale of internal climate-mode signals can substantially bias or contaminate a mean sea-level trend estimate, particularly when the quantum of externally forced sea-level rise (of primary interest) is only around a couple of millimetres per year over both the historical and near-term forecasts.

Secondly, isolating or accommodating the encumbrance of vertical land motion (VLM) embedded within tide gauge records has been addressed as a sensitivity analysis by looking at both the "relative" and "geocentric" rates of sea-level rise at each of the sites considered.

Having removed the influence of internal climate modes (and other contaminating signals), the results would suggest that although the rate of rise in both the AR5 projection modelling and observational SSH data tend to agree $(95 \% \mathrm{CL})$, the mean rates from the ensemble modelling products over the period of common coverage would appear biased on the high side at this point in time.

\section{Data and Methods}

The selection of sites used in this study were based on the existence of tide-gauge records which maximized length and quality (limited gaps and absence of known datum problems) whilst providing regional representativeness and global spatial coverage. Nineteen sites were selected that met these criteria (refer to Figure 1 and Table 1 for more details). Each site has notionally been assigned a station ID commencing with Honolulu (1) in the Central Pacific, progressing west to east to Auckland (19). By graphically representing characteristics associated with records based on the station ID, spatially dominant patterns are more readily apparent.

Annual average time-series data from the public archives of the Permanent Service for Mean Sea Level (PSMSL) [11,12] have been used in the analysis. Extended datasets from the extensive composite time series work by Hogarth (2014) [13] using near-neighbour tide gauge records have been used to augment the PSMSL records. Where possible, every effort has been made to source data up to and including 2016 (refer to Acknowledgements).

AR5 data [5] have been used to extract model ensemble outputs for total projected relative sea-level rise at each site. These data are publicly available in netCDF format from the Integrated Climate Data Center (ICDC) [6] with yearly outputs spanning the period 2007 to 2100 on a spatial resolution grid of $1^{\circ} \times 1^{\circ}$ for the Representative Concentration Pathway (RCP) 2.6, 4.5 and 8.5 experiments. The CMIP5 multi-model ensemble contains only 16 models for the RCP2.6 experiment; however, the RCP4.5 and 8.5 experiments are based on all 21 models (Dr. Mark Carson, Institute of Oceanography, ICDC, University of Hamburg, 2017, pers.comm., 19 June). Time series data for each of the respective RCP experiments have been extracted at the nearest grid point to the respective tide-gauge record, for which there is complete ensemble model coverage (refer Table 1 for details).

Satellite altimeter products by Ssalto/Duacs distributed by Archiving, Validation and Interpretation of Satellite Oceanographic (AVISO), with support from the Centre National d'Etudes Spatiales (CNES) [14] have been used to extract time series of SSH. These data have been made available for this research in netCDF format from the Integrated Climate Data Center (ICDC) [15] with daily outputs spanning the period 1 January 1997 to 6 January 2017 on a spatial resolution grid of $0.25^{\circ} \times 0.25^{\circ}$ (Cartesian). Daily outputs have been converted into annual time series at the nearest grid point to the respective tide gauge record (refer to Table 1 for details) and compared with the tide-gauge record to provide one of the estimates of VLM used in the study.

However, the key initial step in the process is to estimate the externally forced (or climate-change) component by removing the internal climate mode and other higher frequency signals from both the tide-gauge and ensemble projection-model time series. SSA has proven an optimal analytic for this task in sea-level studies [16] as a powerful data adaptive technique capable of decomposing a time series into 
the sum of interpretable components with no a priori information about the time-series structure $[17,18]$. Specifically, SSA can efficiently decompose an original record into a series of components of slowly varying trend, oscillatory components with variable amplitude, and a structureless noise [19].

Following sensitivity testing of parameterisation and visual inspection of individual components from the SSA decomposition across a range of station records and projection-model outputs, the internal climate mode and other higher frequency signals are effectively removed using 1-dimensional SSA, a default-embedding dimension of half the time series length and frequency-thresholding techniques [20] aggregating only components in which the relative contribution in the lowest frequency bin ( 0 to 0.02 cycles per year) is set above a threshold of $\approx 0.80$. Figure 2 highlights the efficiency of these parameter settings in isolating the externally forced component at Fremantle, Australia which was one of the sensitivity-testing sites used for this purpose.
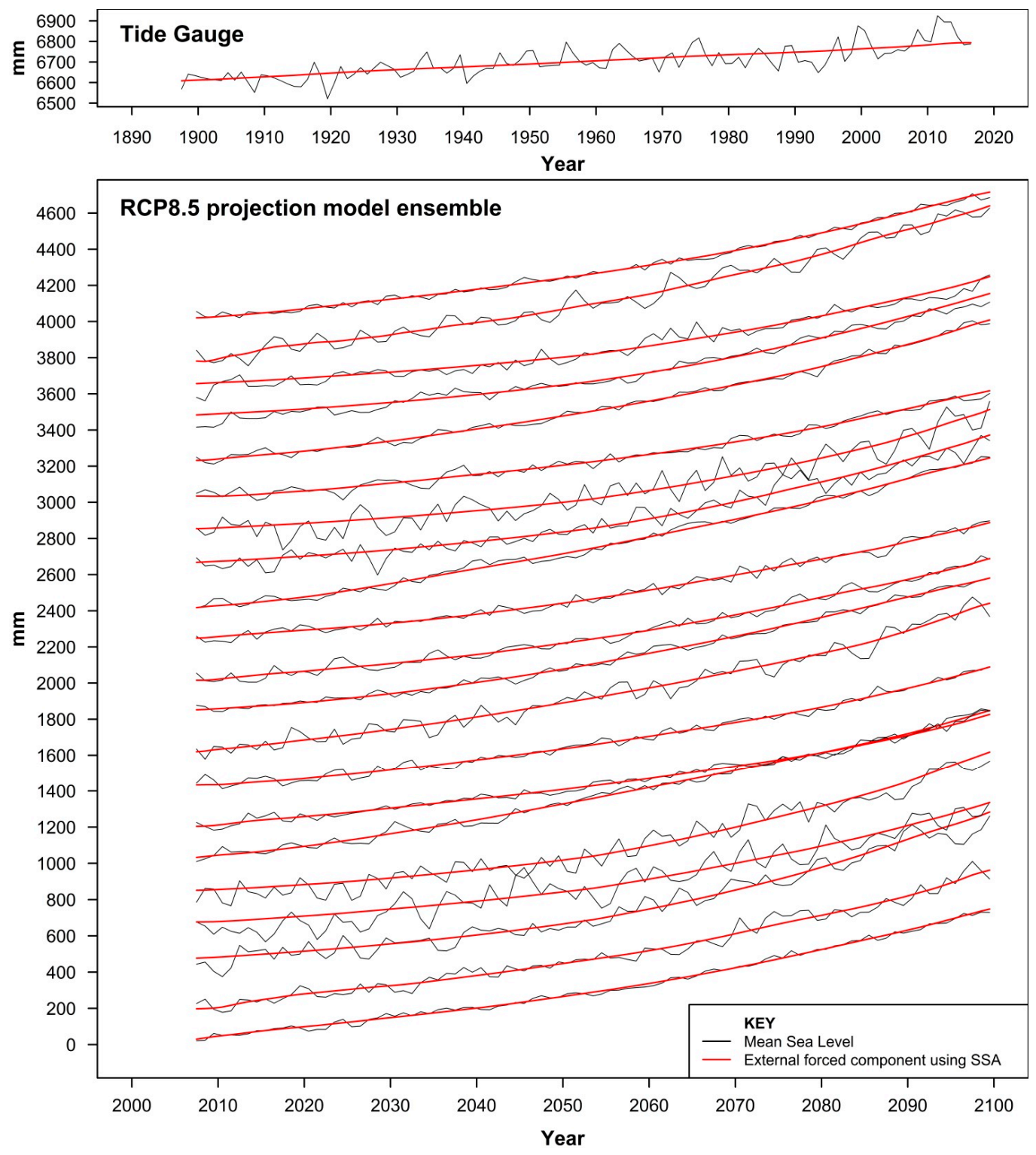

Figure 2. Optimization of singular spectrum analysis (SSA) to isolate the external forced component of both the tide-gauge records and projection-model ensemble. The example from Fremantle, Australia, shows the decomposition of the tide-gauge record in the top panel and all 21 representative concentration pathway (RCP) 8.5 projection-model outputs in the bottom panel. Each time series has been notionally offset vertically in the bottom panel by $200 \mathrm{~mm}$ for clarity. 
Table 1. Summary of tide-gauge, AR5 model-projection and altimetry data used in this study.

\begin{tabular}{|c|c|c|c|c|c|c|c|}
\hline Station ID ${ }^{1}$ & $\begin{array}{l}\text { Tide Gauge } \\
\text { Record }^{2}\end{array}$ & $\begin{array}{c}\text { Start } \\
\text { (year) }^{2}\end{array}$ & $\begin{array}{c}\text { End } \\
\text { (year) }^{2}\end{array}$ & $\begin{array}{c}\text { AR5 Lat } \\
\left({ }^{\circ} \mathrm{N}\right)^{5}\end{array}$ & $\begin{array}{l}\text { AR5 Long } \\
\left({ }^{\circ} \text { E }\right)^{5}\end{array}$ & $\begin{array}{l}\text { Altimetry Lat } \\
\left({ }^{\circ} \mathrm{N}\right)^{6}\end{array}$ & $\begin{array}{l}\text { Altimetry Lat } \\
\left({ }^{\circ} \text { E }\right)^{6}\end{array}$ \\
\hline 1 & Honolulu $^{3}$ & 1891 & 2016 & 21.5 & 202.5 & 21.125 & 202.125 \\
\hline 2 & Prince Rupert ${ }^{3}$ & 1903 & 2016 & 52.5 & 229.5 & 54.125 & 228.875 \\
\hline 3 & Seattle & 1899 & 2016 & 47.5 & 233.5 & 47.375 & 235.125 \\
\hline 4 & San Francisco ${ }^{3}$ & 1855 & 2016 & 37.5 & 236.5 & 37.625 & 237.375 \\
\hline 5 & Key West & 1913 & 2016 & 24.5 & 277.5 & 24.375 & 278.125 \\
\hline 6 & Balboa & 1908 & 2016 & 6.5 & 279.5 & 8.875 & 280.625 \\
\hline 7 & New York $^{3}$ & 1853 & 2016 & 39.5 & 287.5 & 40.375 & 286.125 \\
\hline 8 & Buenos Aires 3,4 & 1905 & 2016 & -36.5 & 304.5 & -34.625 & 301.625 \\
\hline 9 & Brest & 1807 & 2016 & 48.5 & 354.5 & 48.125 & 355.375 \\
\hline 10 & North Shields ${ }^{3}$ & 1895 & 2016 & 55.5 & 0.5 & 54.875 & 358.875 \\
\hline 11 & Karachi & 1868 & 2014 & 23.5 & 66.5 & 24.625 & 66.875 \\
\hline 12 & Mumbai & 1878 & 2012 & 18.5 & 71.5 & 18.875 & 72.675 \\
\hline 13 & Ko Taphao Noi & 1940 & 2016 & 7.5 & 96.5 & 7.625 & 98.375 \\
\hline 14 & Fremantle & 1897 & 2016 & -32.5 & 114.5 & -32.125 & 115.625 \\
\hline 15 & Hosojima & 1930 & 2016 & 31.5 & 133.5 & 32.375 & 131.875 \\
\hline 16 & Aburatsubo & 1930 & 2016 & 33.5 & 139.5 & 31.625 & 131.625 \\
\hline 17 & Sydney & 1886 & 2016 & -33.5 & 153.5 & -33.875 & 151.375 \\
\hline 18 & Dunedin 3 & 1900 & 2016 & -45.5 & 172.5 & -46.125 & 170.375 \\
\hline 19 & Auckland & 1899 & 2016 & -35.5 & 176.5 & -36.675 & 174.875 \\
\hline
\end{tabular}

${ }^{1}$ Station ID ordered moving west to east commencing at Honolulu, HI, USA (refer Figure 1). ${ }^{2}$ Permanent Service for Mean Sea Level (PSMSL) annual average data used in this study $[11,12] .{ }^{3}$ PSMSL data has been further extended by Hogarth (2014) [13]. ${ }^{4} 2015$ and 2016 data added to Hogarth (2014) [13] by filling from comparison with nearby Palermo station record which dates back to $1960 .{ }^{5}$ Nearest projection-model output to tide-gauge record with complete ensemble coverage. ${ }^{6}$ Nearest satellite altimetry grid point to tide-gauge record with complete coverage. Altimeter products by Ssalto/Duacs distributed by Aviso, with support from Centre National d'Etudes Spatiales (CNES) [14].

All analysis and graphical outputs have been developed by the author from customized scripting code within the framework of the R Project for Statistical Computing [21] and are available upon request. The applied methodology can be appropriately partitioned into analysis of the historical tide-gauge record and that of the AR5 ensemble projection-model outputs. The selection and application of SSA and other key steps in the analysis are broadly underpinned by unprecedented time-series research, development, and analysis of ocean water-level data [16,22-26].

\subsection{Historical Tide-Gauge Analysis}

The methodology applied in analysing the observational tide gauge records can be broadly summarised in the following 5 steps:

Step 1: Gap-filling of time series. This is a necessity in order to decompose the time series using SSA. Whilst the longest and most complete tide-gauge records have been used for analysis, missing data persists in several records. Where required, records have been filled using an iterative SSA procedure [27] in the first instance, which has an (assumed) advantage in preserving the principal spectral structures of the complete portions of the original data set in filling the gaps. Station records filled using this procedure included Prince Rupert, Key West, Balboa, North Shields, Mumbai, Ko Taphao Noi, Hosojima, Aburatsubo, Sydney and Auckland. Visual inspection confirmed the suitability of the gap-filled sections. Where this method provided visually unreliable results, gaps were filled using the comparatively simpler Stineman's interpolation [28]. This procedure was suitably applied to the Brest, Fremantle and Dunedin records.

Step 2: Estimation of "relative" mean sea level. Having necessarily filled time series in Step 1, the record is decomposed using 1 dimensional SSA to isolate components of slowly varying trend (i.e., mean sea level due to external climate forcing) from oscillatory components with variable amplitude, and noise. As advised earlier, frequency thresholding has been used to facilitate this step with mean sea level estimated by summing the components of the SSA decomposition in which the relative contribution in the lowest frequency bin [0-0.02] exceeds 0.80 . 
Step 3: Estimation of average "relative" mean sea-level velocity over period of common coverage (post 2007). For all but 2 of the records considered (Karachi and Mumbai), the period of common coverage between the tide-gauge records and the projection-model outputs extends from 2007 to 2016. The average "relative" velocity over this period has been determined by simple linear least squares regression of the respective portion of the time series determined in Step 2.

Step 4: Estimation of errors. This process initially involves fitting an autoregressive time-series model to remove the serial correlation in the residuals between the SSA derived trend (Step 2) and the gap-filled time series (Step 1). The estimation of error in the average "relative" mean sea-level velocity is then based on bootstrapping techniques where the uncorrelated residuals are randomly recycled and the process in steps 2 and 3 is repeated 1000 times. From the extensive pool of outputted relative velocities, standard deviations are readily calculated to derive robust confidence intervals.

Step 5: Correction to estimate "geocentric" velocity. The correction from "relative" to "geocentric" velocity has been undertaken using 3 separate estimates for VLM as a form of sensitivity analysis given the general uncertainty with this parameter. The first method (referred to hereafter as "Type 1") uses VLM estimates provided by Systeme d'Observation Du Niveau Des Eaux Littorales (SONEL) based on continuous global-positioning system (GPS) measurements of the land mass in the vicinity of the tide gauge $[29,30]$. However, "Type 1" VLM rates are only available for 12 of the 19 tide gauge records. The second method estimates VLM considering the difference between the tide-gauge record and that of the nearest gridded data time series from satellite altimetry using the approach of Ostanciaux et al. (2012) [31]. This second method (referred to hereafter as "Type 2") estimates VLM from the linear regression of the difference in the annualised time series of both data sets providing a VLM estimate for every station record considered. A third method (referred to hereafter as "Type 3") proposed by Pfeffer and Allemand (2016) [32], estimates VLM via a similar approach to Ostanciaux et al. (2012) [31] with some further advancements to the time-series analysis procedure, providing a VLM estimate for 15 of the 19 station record considered. VLM rates applied in this study are summarised in Table 2. Error margins in quantifying "geocentric" velocity are calculated in quadrature by combining the error in the VLM rates with those determined in Step 4.

\subsection{AR5 Sea Surface-Height (SSH) Projection-Model Output Analysis}

The following methodology has been applied to the AR5 projection modelling SSH data products for RCP2.6, 4.5 and 8.5 experiments, to assimilate and compare them to the observational tide gauge data:

Step 1: Estimation of "relative" mean sea level. The same SSA procedure advised for the tide gauge records is then applied to the projection-model ensemble products to remove the internal variability and other dynamic signals in order to isolate the slowly varying trend (i.e., mean sea level due to external climate forcing). As advised previously, the SSH projection-modelling outputs used in AR5 [5], made available by the ICDC [6], are already provided as "relative" sea-level products. This was done by inverting an allowance for GIA and applying this "correction" to the original "geocentric" model outputs. The GIA allowance used in AR5 for this purpose was an average of both the Peltier (2004) [33] and Lambeck et al. (1998) [34] estimates (see Table 2 for details). With the internal variability (and other high-frequency signals) removed, the ensemble mean has been used to normalise projection-model outputs to each of the respective tide-gauge datums. The ensemble model SSH output products are based on a 20-year moving average with the modelling start point set at 1986-2005 (i.e., centred around 1995). The annual time series output products from the ICDC for AR5 start at 2007 and have therefore been normalized to each of the respective tide-gauge records by using the mean sea-level estimate in 1995.

Step 2: Estimation of average "relative" mean sea-level velocity over period of common coverage (post 2007). The same process advised for the tide-gauge analysis has been applied to each of the outputted time series from Step 1 (above), providing a pool of 16 outputted velocities over the period of common coverage for the RCP2.6 experiment, and 21 outputted velocities for the RCP 4.5 and 
8.5 experiments at each location. The average "relative" mean sea-level velocity at each location, for each of the respective RCP experiments, is then determined simply from the mean of each of the outputted pool of velocities. The associated errors are also readily determined from the standard deviation of the pool of outputted velocities.

Table 2. Summary of vertical land motion (VLM) and glacial isostatic adjustment (GIA) rates used in this study.

\begin{tabular}{|c|c|c|c|c|c|c|}
\hline Station ID ${ }^{1}$ & Site & $\begin{array}{c}\text { Peltier GIA } \\
\text { (mm/Year) }\end{array}$ & $\begin{array}{c}\text { AR5 GIA }{ }^{2,4} \\
(\mathrm{~mm} / \text { Year })\end{array}$ & $\begin{array}{c}\text { Type } 1 \text { VLM }{ }^{2,5} \\
(\mathrm{~mm} / \text { Year) }\end{array}$ & $\begin{array}{c}\text { Type } 2 \text { VLM } \\
\text { (mm/Year) }\end{array}$ & $\begin{array}{c}\text { Type } 3 \text { VLM } \\
\text { (mm/Year) }\end{array}$ \\
\hline 1 & Honolulu & -0.17 & $0.23 \pm 0.07$ & $-0.23 \pm 0.18$ & $-0.84 \pm 0.52$ & $0.30 \pm 0.31$ \\
\hline 2 & Prince Rupert & 0.33 & $0.64 \pm 0.51$ & NA & $0.56 \pm 1.17$ & $-2.10 \pm 0.93$ \\
\hline 3 & Seattle & -1.10 & $-0.99 \pm 0.59$ & $-0.99 \pm 0.22$ & $-0.27 \pm 0.75$ & $-0.99 \pm 0.65$ \\
\hline 4 & San Francisco & -1.00 & $-0.73 \pm 0.61$ & $-0.04 \pm 0.15$ & $0.37 \pm 0.64$ & $0.27 \pm 0.86$ \\
\hline 5 & Key West & -0.75 & $-0.65 \pm 0.52$ & $-1.76 \pm 0.43$ & $-1.23 \pm 0.92$ & $-1.18 \pm 0.66$ \\
\hline 6 & Balboa & -0.26 & $0.04 \pm 0.08$ & NA & $7.55 \pm 1.93$ & $1.89 \pm 1.85$ \\
\hline 7 & New York & -1.80 & $-1.39 \pm 0.43$ & $-2.12 \pm 0.62$ & $0.96 \pm 1.37$ & $-1.95 \pm 0.89$ \\
\hline 8 & Buenos Aires & 0.70 & $0.29 \pm 0.16$ & $1.03 \pm 0.24$ & $0.84 \pm 1.80$ & NA \\
\hline 9 & Brest & -0.60 & $-0.48 \pm 0.12$ & $0.01 \pm 0.11$ & $-0.64 \pm 0.85$ & $-1.60 \pm 0.59$ \\
\hline 10 & North Shields & 0.11 & $0.10 \pm 0.27$ & $1.39 \pm 0.67$ & $0.46 \pm 0.75$ & $-0.72 \pm 0.61$ \\
\hline 11 & Karachi & 0.33 & $0.06 \pm 0.17$ & NA & $-2.53 \pm 0.44$ & NA \\
\hline 12 & Mumbai & 0.31 & $0.14 \pm 0.18$ & NA & $0.61 \pm 2.17$ & NA \\
\hline 13 & Ko Taphao Noi & 0.16 & $0.13 \pm 0.10$ & NA & $-9.51 \pm 2.40$ & $-3.12 \pm 1.83$ \\
\hline 14 & Fremantle & -0.33 & $0.07 \pm 0.01$ & NA & $-0.30 \pm 0.66$ & $-0.76 \pm 0.71$ \\
\hline 15 & Hosojima & 0.43 & $0.26 \pm 0.11$ & NA & $1.33 \pm 0.59$ & $0.59 \pm 0.79$ \\
\hline 16 & Aburatsubo & 0.47 & $0.31 \pm 0.10$ & NA & $-1.48 \pm 1.29$ & $-2.58 \pm 0.67$ \\
\hline 17 & Sydney & -0.23 & $0.02 \pm 0.06$ & $-0.33 \pm 0.25$ & $-1.27 \pm 0.98$ & $2.12 \pm 0.75$ \\
\hline 18 & Dunedin & -0.02 & $0.20 \pm 0.04$ & $-1.02 \pm 0.12$ & $-1.53 \pm 0.61$ & $0.46 \pm 0.47$ \\
\hline 19 & Auckland & 0.03 & $0.17 \pm 0.01$ & $-0.62 \pm 0.23$ & $-1.24 \pm 0.80$ & NA \\
\hline
\end{tabular}

${ }^{1}$ Refer to Figure 1 and Table 1 for further details. ${ }^{2}$ Error margins advised are standard errors (i.e., $\left.1 \sigma\right) .{ }^{3}$ Peltier GIA estimates [33] at tide-gauge sites available from PSMSL [12]. Aligned with VLM prediction for consistency (i.e., positive is up, negative down). ${ }^{4}$ AR5 GIA estimates based on average of Peltier [33] and Lambeck [34] provided by Integrated Climate Data Center (ICDC) [6] and aligned with VLM prediction for consistency (i.e., positive is up, negative down). Gridded error margins for the GIA estimates are also provided by ICDC. ${ }^{5}$ Type 1 VLM estimates are based on ULR6 global-positioning system (GPS) solutions [30] provided by Systeme d'Observation Du Niveau Des Eaux Littorales (SONEL) [29]. ${ }^{6}$ Type 2 VLM estimates are based on the difference between the annual time series from satellite altimetry [14] and the tide gauge using the procedure advised in Ostanciaux et al. (2012) [31].

${ }^{7}$ Type 3 VLM estimates are based on the procedure advised in Pfeffer and Allemand (2016) [32].

Step 3: Correction to estimate "geocentric" velocity. The correction from "relative" to "geocentric" velocity is straightforward, requiring merely the addition of the respective gridded GIA allowance discussed in Step 2 above to the average "relative" mean sea-level velocity determined in Step 2 (refer Table 2 for AR5 GIA estimates). Error margins in quantifying "geocentric" velocity are calculated in quadrature by combining the error in the AR5 GIA rates with those determined in the "relative" mean sea-level velocity in Step 2.

\section{Results}

The results of the analysis are graphically represented in Figures 3-6. Figure 3 summarises the average "relative" velocity determined over the period of common coverage at each location, directly comparing estimates derived from the observational tide-gauge record with those derived from the model ensemble of SSH projections used in AR5 for each of the respective RCP experiments. From this analysis, at the $95 \%$ confidence level depicted, the observational and model-projected average velocity agree for 18 of the 19 records for all RCP experiments (excluding only Balboa, Panama). However, owing to the comparatively large error margins, particularly for the model-ensemble products, the mean velocity for the model-projection products are higher than the mean of the observational records for 16 of 19 stations across all RCP experiments. For these 16 records, the average gap is in the range of 1.6-1.8 mm/year. When all station records are considered across all RCP experiments the average gap is slightly lower, in the range of $1.2-1.4 \mathrm{~mm} /$ year.

Figure 4 summarises the average "geocentric" velocity analysis using the "type 1" VLM correction for the tide gauge records. However, it should be noted that there are only 11 tide gauge records 
where direct GPS VLM measurements are available for this analysis. Of these records, at the 95\% confidence level depicted, the observational and model-projected average velocity agree across all RCP experiments. However, similar to the "relative" velocity analysis, the mean "geocentric" velocity for the model-projection products are higher than the mean of the observational records for all 11 records with Type 1 VLM corrections available, across all RCP experiments. For these 11 records, the average gap is similarly in the range of $1.6-1.8 \mathrm{~mm} /$ year.

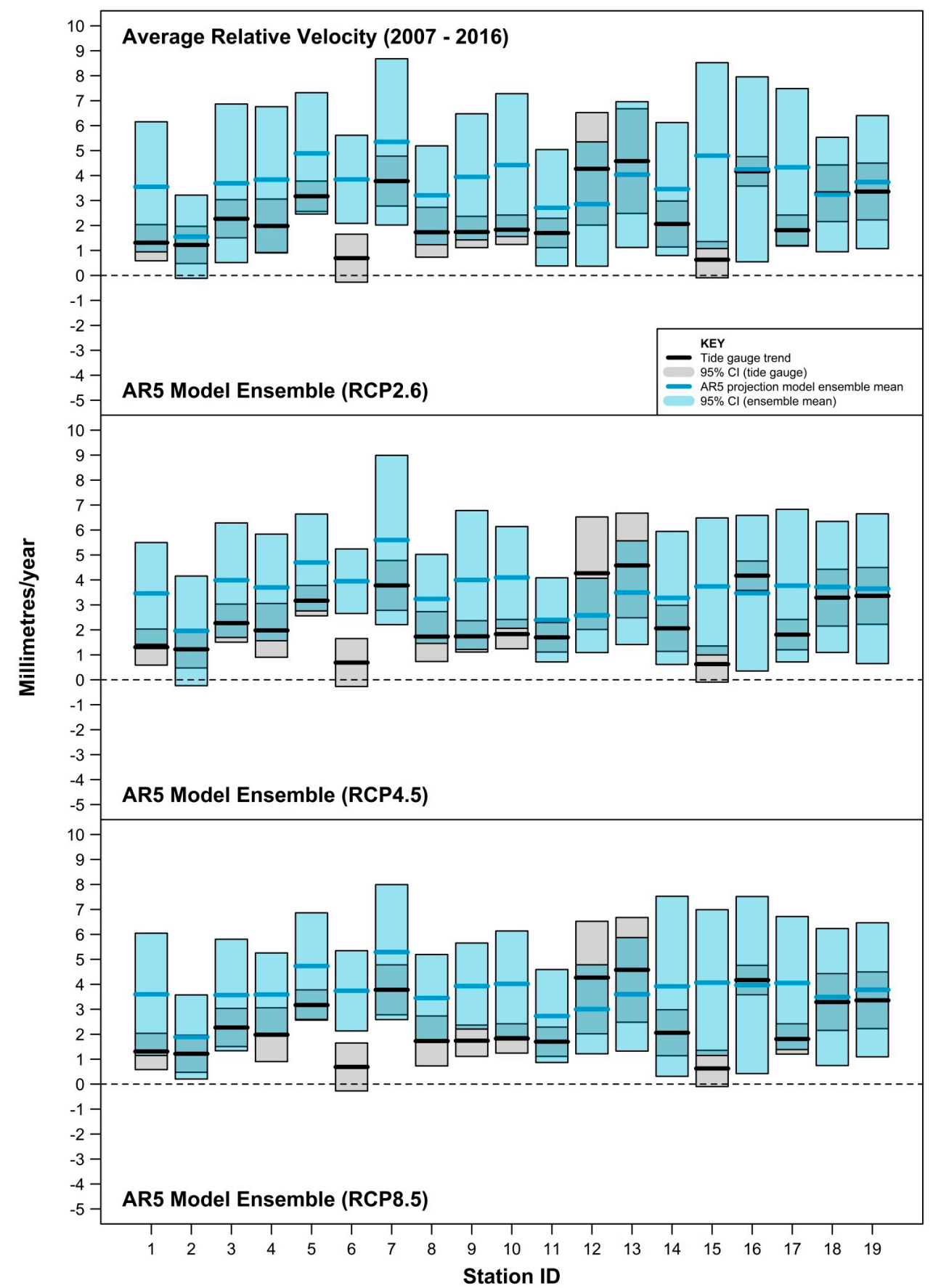

Figure 3. Average "relative" velocity determined over the period of common coverage (2007-2016). These charts directly compare the observational record (tide-gauge analysis) and corresponding AR5 ensemble-model projections at the grid point of interest. Refer to Figure 1 and Table 1 for station ID details. 


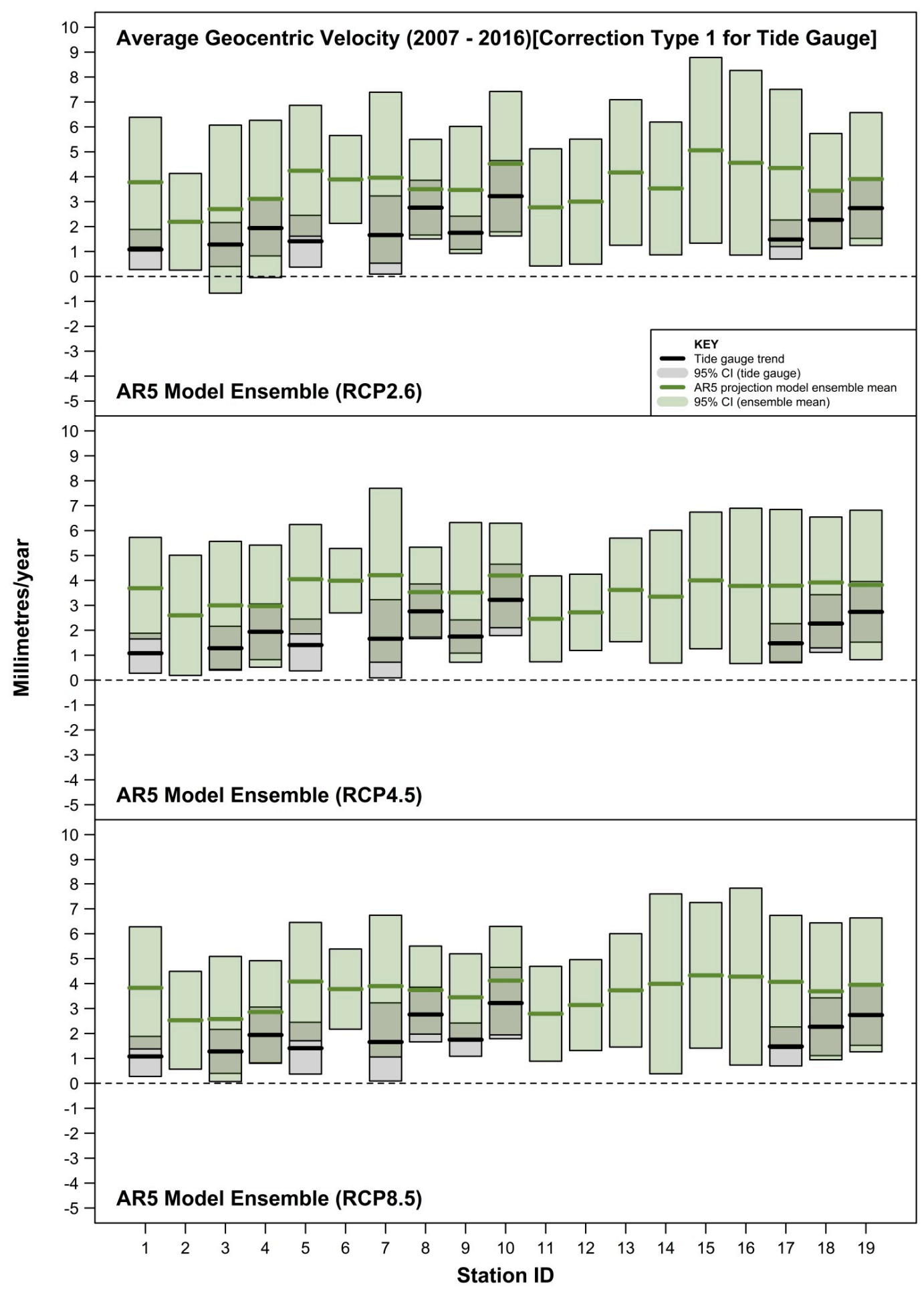

Figure 4. Average "geocentric" velocity determined over the period of common coverage (2007-2016) using Type 1 correction for VLM. Type 1 corrections are based on direct GPS measurements at or near the tide gauge. These charts directly compare the observational record (tide-gauge analysis) and corresponding AR5 ensemble-model projections at the grid point of interest. Refer to Figure 1 and Table 1 for station ID details. 


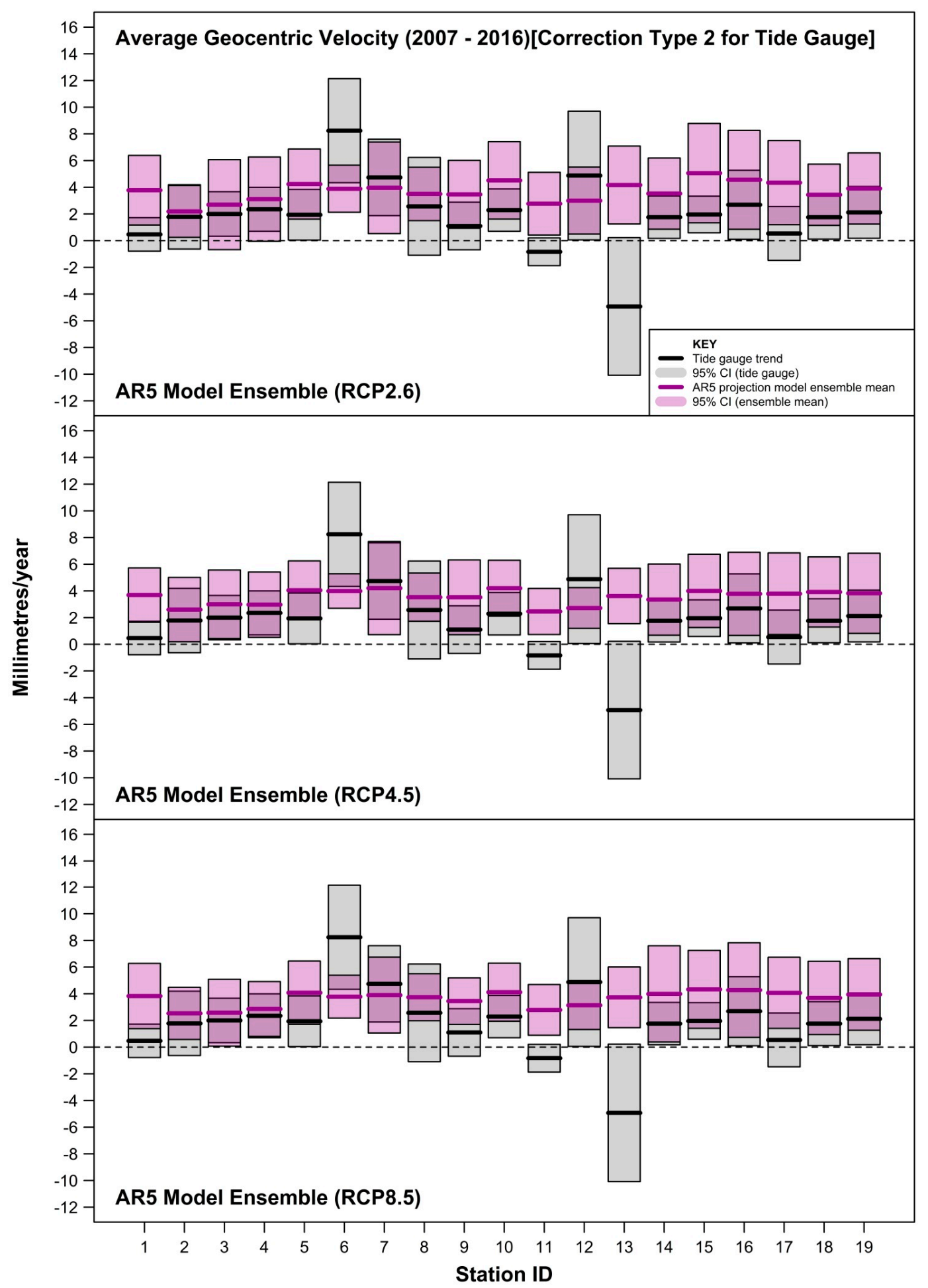

Figure 5. Average "geocentric" velocity determined over the period of common coverage (2007-2016) using Type 2 correction for VLM. Type 2 corrections are based on differences between altimetry and the tide-gauge records via the procedure advised in Ostanciaux et al. (2012) [31]. These charts directly compare the observational record (tide-gauge analysis) and corresponding AR5 ensemble-model projections at the grid point of interest. 


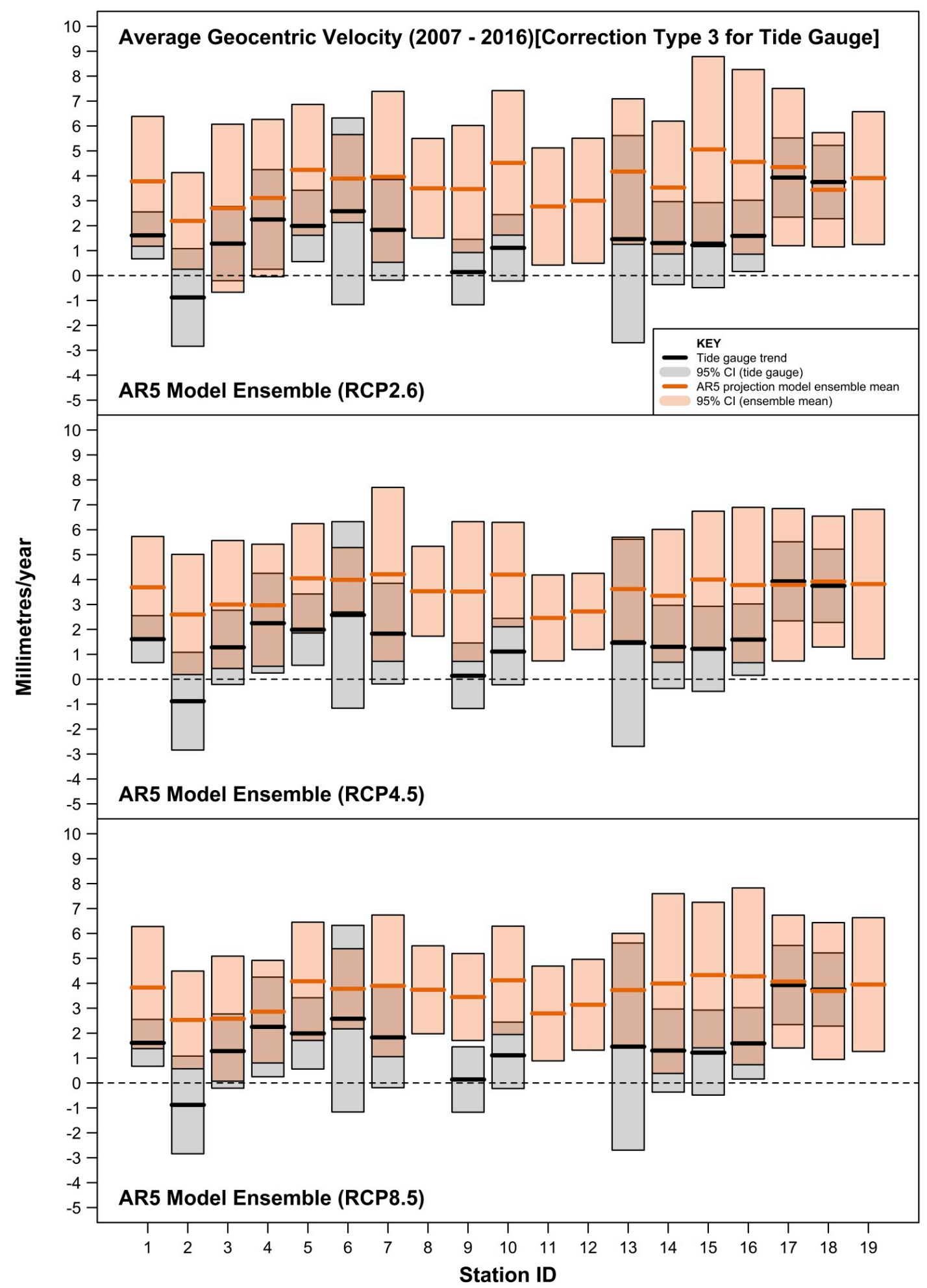

Figure 6. Average "geocentric" velocity determined over the period of common coverage (2007-2016) using Type 3 correction for VLM. Type 3 corrections are based on differences between altimetry and the tide-gauge record advised by Pfeffer and Allemand 2016 [32]. These charts directly compare the observational record (tide-gauge analysis) and corresponding AR5 ensemble-model projections at the grid point of interest. Refer to Figure 1 and Table 1 for station ID details. 
Figure 5 summarises the average "geocentric" velocity analysis using the "type 2" VLM correction for the tide-gauge records, which is estimated from the difference between the satellite altimetry and tide-gauge record. Unlike, "type 1" VLM estimates, the "type 2" method provides consistent estimates for all sites based on nearly 20 years of altimetry records. From this analysis, at the $95 \%$ confidence level depicted, the observational and model-projected average velocity agree for 18 of the 19 records for all RCP experiments (excluding only Ko Taphao Noi, Thailand where ground subsidence is prevalent). As with the aforementioned analyses, the mean "geocentric" velocity for the model-projection products are higher than the mean of the observational records for 16 of 19 stations across all RCP experiments. For these 16 records, the average gap is in the range of $2.3-2.5 \mathrm{~mm} /$ year. When all station records are considered across all RCP experiments the average gap reduces to around 1.5-1.8 mm/year.

Figure 6 summarises the average "geocentric" velocity analysis using the "type 3" VLM correction for the tide-gauge records, which is estimated via the process espoused in Pfeffer and Allemand 2016 [32], although it should be noted that there are only 15 sites where "type 3" corrections are available for analysis. From this analysis, at the 95\% confidence level depicted, the observational and model-projected average velocity agree for all stations across all RCP experiments with the exception of only Brest, France, for the RCP 8.5 experiment whereby the observational record was lower than the projection-model average. Similar to the other VLM sensitivity analyses, the mean "geocentric" velocity for the model-projection products are higher than the mean of the observational records for 14 of 15 stations with "type 3" VLM corrections available, across all RCP experiments. For these 14 records, the average gap is in the range of $2.0-2.3 \mathrm{~mm} /$ year. When all station records are considered across all RCP experiments the average gap is slightly lower, in the range of $1.9-2.2 \mathrm{~mm} /$ year.

\section{Discussion}

There will always be difficulties associated with comparing rates of change in SSH from observational and projection-modelling sources for the comparatively short timeframe (2007-2016) available. For this reason, different "relative" and "geocentric" velocity comparisons have been undertaken to provide a sensitivity test for the results of the analysis. However, it is worthwhile noting that the error margins associated with the respective data analyses, particularly those involving the ensemble projection-modelling products, are comparatively large. Given that subtle emerging trends might risk being obscured by the width of the confidence margins depicted (95\%), further analysis has been undertaken using $80 \%$ confidence intervals as a further sensitivity check. At the narrower confidence levels, a clearer trend emerges whereby up to 6 of the 19 station records for the "relative" velocity assessment highlight observational records that are statistically lower than the projection-modelled products across all RCP experiments. For the "geocentric" velocity assessment using the 11 station records with "Type 1" VLM corrections available, some 4 records indicate observational velocities statistically lower than the projection-modelled products $(80 \% \mathrm{CL})$.

Similarly for the "geocentric" velocity assessment using the full coverage "Type 2" VLM corrections, 6 of the observational records are statistically different to the projection-modelling products, with 5 being lower $(80 \% \mathrm{CI})$. When "type 3" VLM corrections are applied, 4 observational records exhibit a "geocentric" velocity statistically different to the projection-modelling products, with all being lower. Across the majority of analysis types and RCP experiments at the $80 \%$ confidence level, 4 sites consistently emerge for which the projection-modelling products are statistically higher than the observational data record over the period of common coverage: Honolulu (USA), Key West (USA), Brest (France) and Sydney (Australia).

From the analysis undertaken, evidence suggests the AR5 projection-model outputs for SSH appear to be rising at a faster rate than the observational (tide gauge) records over the decade of common coverage. AR5 alluded to this possibility noting that for the global mean sea-level analysis, the rate of rise at the start of the RCP projections was about $3.7 \mathrm{~mm} /$ year, slightly above the observational (altimetry) range of $3.2 \pm 0.4 \mathrm{~mm}$ /year for 1993-2010, surmising the simulated rate of climate warming being greater than that observed [5]. The current analysis, benefitting from improved 
time-series analysis techniques across 19 global sites with good global spatial coverage, observes a wider difference at site-specific (or regional) scales.

Although the overlapping period (2007-2016) of coverage of both types of data permit a decade over which relevant comparisons can be made between observational and projection-modelling products, one should appreciate the conclusions of the work at this point in time have particular caveats and limitations which might include (but not be limited to):

- AR5 projection-model outputs were not designed to be necessarily rigorous at the decadal time scale;

- an overlapping decade is a relatively small window over which to compare the characteristics of long-term phenomena such as mean sea-level rise. Furthermore, time-series analysis techniques are ubiquitously affected by end effects and the analysis herein is attempting to investigate and compare the characteristics of the end of one time series (tide-gauge data to present) with the start of another (AR5 projections from 2007);

- estimating and accommodating the ubiquity of VLM resulting from multiple origins (including tectonics, subsidence, etc., as well as GIA) embedded within tide-gauge records. As evident in this study, co-located GPS measurements are not available for many tide-gauge sites or are at best quite short records (often $<10$ years) [29,30]. The more complete and longer VLM estimates based on the method of Ostanciaux et al. 2012 [31] are reliant on satellite altimetry data [14] on a spatial resolution grid of $0.25^{\circ} \times 0.25^{\circ}$ and could be a maximum of $\approx 20 \mathrm{~km}$ from the tide-gauge site. Similarly, the AR5 approach of correcting projection outputs for GIA to better approximate mean sea-level rise "relative" to the land ignores the many other VLM origins present at tide-gauge sites. This is highlighted clearly in Figure 7, where the GIA estimates at Balboa [ID =6] and Ko Taphao Noi [ID = 13] differ markedly from the actual VLM observed via differing techniques. At both sites, the estimated GIA is $<0.2 \mathrm{~mm}$ /year, whereas the VLM associated with the tectonic uplift of the Panama Arc at Balboa [35] and subsidence due to groundwater and aquifer mining at Ko Taphao Noi [36] are of the order of several mm/year;

- the highest density of long tide-gauge records are predominantly clustered around Europe and North America in the northern hemisphere [25]. There is only a relatively small pool of records available outside these domains with sufficient length and apparent robustness (i.e., absence of warning flags in the PSMSL database) to consider for meaningful global coverage; and

- the postulated theory that the Mt Pinatubo eruption in the Philippines in 1991 has had the effect of masking (or delaying) the rate of global sea-level rise [37] which would also be reflected in the tide-gauge records.

Notwithstanding the aforementioned issues, the analysis undertaken of tide-gauge records and projection-modelling outputs permits one to take advantage of their considerable length, enabling the application of improved time-series techniques to isolate the trend (associated with external climate forcing) from the contaminating dynamic influences that persist on decadal to multi-decadal and longer cycles [38-43]. By comparison, the altimetry products used to evaluate the CMIP5 SSH projection-model outputs [4], though having the advantage of broad ocean coverage to a fixed reference datum, have limited utility in separating out the aforementioned type of contaminating influences on longer timescales owing to shortness of the records at this point in time (post late 1992). 


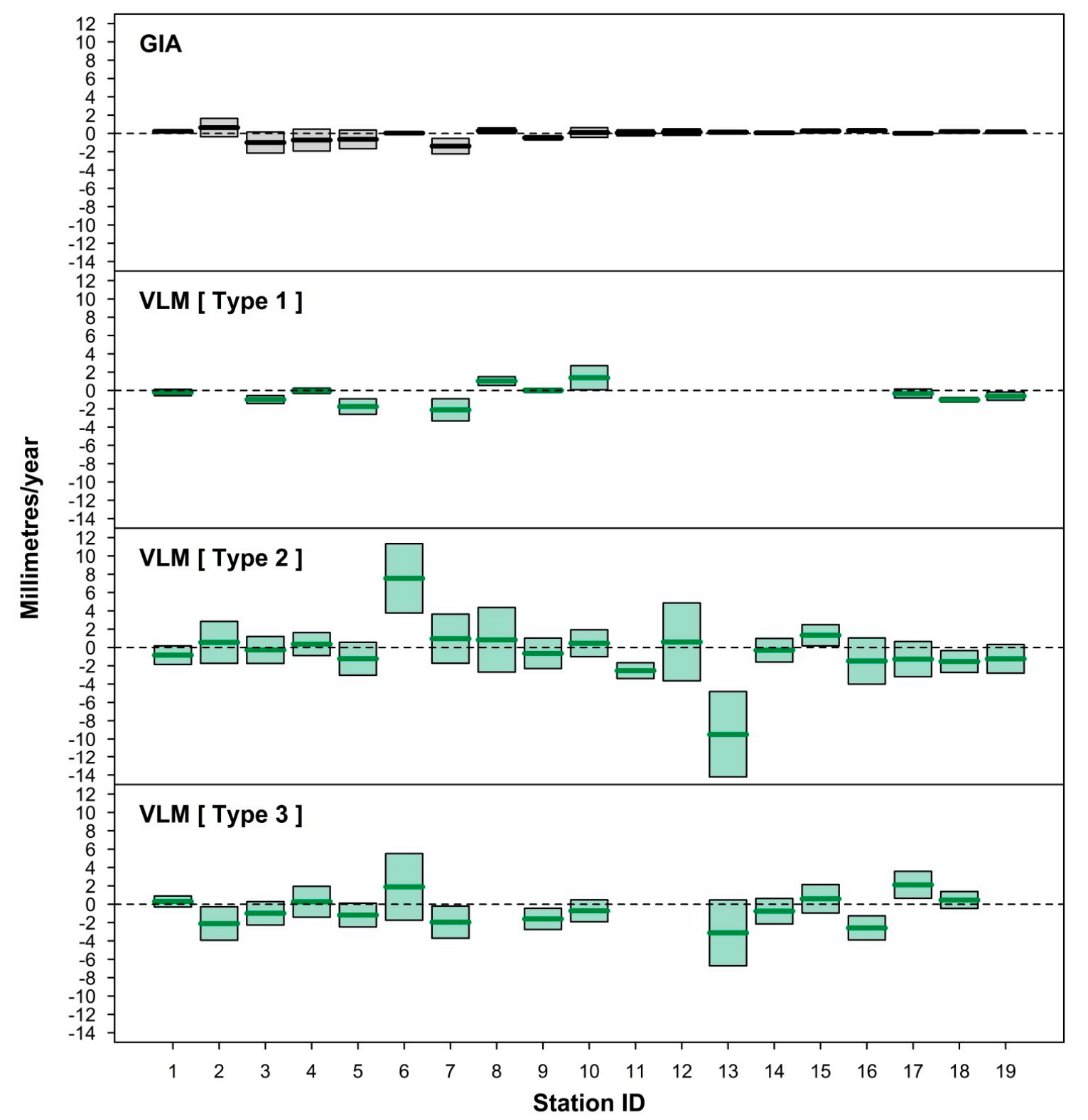

Figure 7. Comparison of VLM and GIA rates for each station record. GIA estimates are those used in AR5 [5] based on an average of Peltier [33] and Lambeck [34] provided by ICDC [6]. "Type 1" VLM are based on ULR6 GPS solutions [30] provided by SONEL [29]. "Type 2" VLM are based on the difference between the annual time series from satellite altimetry [14] and the tide gauge using the procedure advised in Ostanciaux et al. (2012) [31]. "Type 3" VLM are based on the procedure advised in Pfeffer and Allemand (2016) [32]. Error margins depicted in each panel are 95\% CL. Refer to Figure 1 and Table 1 for station ID details.

It is worthwhile appreciating differences between the current paper and the contemporary analysis undertaken in Meyssignac et al. (2017) [10]. This recently published work compared 20th-century regional sea-level trends between an ensemble of 12 climate-model simulations using enhanced input on a range of sea-level contributions and that of 29 tide-gauge observations. This work concluded a general agreement between simulated sea-level and tide-gauge records in terms of interannual to multidecadal variability over the period 1900-2015. It is worth appreciating that this work acknowledges that the trends determined from the tide-gauge records are potentially dominated by decadal to multidecadal internal variability, and that the trend analysis of both types of data 
relies on simple linear regression techniques applied over the period corresponding to the available tide-gauge record (Dr. Benoit Meyssignac, Laboratoire d'Etudes en Géophysique et Océanographie Spatiales, 2017, pers.comm., 12 October). By comparison, this current study takes advantage of more advanced techniques to first remove the influence associated with decadal to multidecadal internal variability from both the tide-gauge data and AR5 projection-model ensembles of sea surface heights before comparing the results for the decade of common coverage (2007-2016). Both studies provide broad agreement between observational and simulated sea levels when error margins are taken into consideration and within the limits of the respective analyses undertaken. A logical next step might be to reapply the techniques espoused in this paper to the gridded outputs of the enhanced climate-model simulations developed in Meyssignac et al. (2017) [10] when they are available.

\section{Conclusions}

The utility and importance of climate models continues to grow in line with strengthening evidence of a changing climate system [2,44-47], in order to provide credible projections for risk assessment (e.g., [48-50]) to guide necessary policy development, mitigation and adaptation responses. The climate models themselves are an integral tool in understanding and interpreting the complex science and interrelationships of Earth systems and climate.

Despite the increasing complexity and resolution of these models, their utility for future projections will always be conditional on their ability to replicate historical and recent observational global and regional data trends of importance (such as temperature, sea level, $\mathrm{CO}_{2}$ trends, etc.).

This paper provides a snapshot of how closely current rates of sea-level rise from observational data records (tide gauges) are represented by the ensemble mean of the AR5 model-projection products at the regional scale, considering 19 sites across the global ocean over the period of common coverage (2007-2016). The application of SSA (described in Section 2) provides the means by which to efficiently isolate the externally (or climate-change) forced signal from all other contaminating dynamic influences (including internal climate modes) for both types of data. This represents a significant improvement in overcoming the bias associated with trend comparisons in the presence of internal climate mode influences.

Corrections for VLM based on the difference between the tide-gauge record and satellite altimetry permit a more consistent approach for correcting the "relative" velocity from the tide-gauge record to "geocentric" rates for direct comparison to the projection-model outputs. With such corrections, it could be concluded that the observational and model-projected average velocity agree across all RCP experiments at the $95 \%$ confidence level. However, the error margins are quite wide, masking the fact that the mean "geocentric" velocity for the model-projection products are higher than the mean of the observational records for nearly all stations across all RCP experiments, and are likely in the range of $1.6-2.5 \mathrm{~mm}$ /year. At the $95 \%$ confidence level across all RCPs, there is no clear spatial pattern to the larger differences between the mean velocities of projection model outputs and the observational records.

Different VLM estimates have been considered as a sensitivity analysis in this paper with all respective analyses confirming similar results and providing more robustness to the general findings herein. However, significant discrepancies have been observed between various VLM estimates at the sites under consideration in this paper. Notwithstanding this, every effort should be made to continue investigating methodologies to make better use of the lengthening satellite altimetry records in this regard, with benchmarking against direct GPS measurements, such as espoused in Pfeffer and Allemand (2016) [32], which will continue to augment and improve the utility of the long tide-gauge records available.

The analysis within this study might provide an early warning sign that the evaluation of ocean model components with respect to projected mean sea level could be relevantly improved. In addition to integrating more advanced oceanographic phenomena at increasingly finer resolution into the ocean model components (e.g., [8-10]), the techniques espoused might also be considered 
part of the evolutionary process by which to improve the robustness and veracity of these critical projection-modelling tools at increasingly finer resolution over the course of CMIP6 [3] and AR6 [7]. With the rate of sea-level rise (or velocity) a key parameter upon which to evaluate model outputs, the lengthy tide-gauge records provide an additional level of enhanced capacity in this regard at increasingly finer resolution.

This situation could be further improved by augmenting the available records in the global data repository of the PSMSL through:

- searching for additional tide-gauge data records of sufficient length (at least 75-80 years) to improve the global spatial coverage of the station records used in this paper, in particular around important margins including the southern coasts of the African continent and along the coastlines of China;

- investigating methods to fill long records in other key areas such as Aden, Yemen (dating back to 1879) and Takoradi, Ghana (dating back to 1930), supplementing the critical work already undertaken to extend PSMSL records (e.g., [13]); and

- contributing data custodians ensuring up-to-date data is supplied in a timely manner.

Supplementary Materials: The Supplementary Materials are available online at http:/ /www.mdpi.com/20771312/6/1/11/s1.

Acknowledgments: This research work has not benefitted from any grants or financial assistance. The author would like to thank the following (in alphabetical order):

- David Bate and Port of Auckland Limited (Auckland, New Zealand) for permitting access to recent data for Auckland;

- Mark Carson (Institute of Oceanography, University of Hamburg, Germany) who provided advice on specifics of the SSH projection-model outputs used in AR5, made available via the Integrated Climate Data Center, University of Hamburg;

- James Chittleborough (Tidal Unit, Bureau of Meteorology, Australia) for providing recent data at Fremantle and Sydney;

- Stefan Kern (Institute of Oceanography, University of Hamburg, Germany) who provided access to the Ssalto/Duacs satellite altimetry products. The altimeter products were produced by Ssalto/Duacs in collaboration with LOcean and CTOH and distributed by Aviso, with support from Cnes (http:/ / www.aviso. altimetry.fr/);

- Glen Rowe, LINZ (Land Information, New Zealand) for providing recent data at Dunedin and Auckland;

- Thiago Dos Santos (Land and Atmospheric Science, University of Minnesota, MN, USA) who provided advice on R scripting code to facilitate extraction of data from netCDF format files;

- Aimée Slangen (Royal Netherlands Institute for Sea Research, The Netherlands) for wide-ranging advice and discussions on climate-modelling products that improved the study; and

- $\quad$ PSMSL, ICDC and SONEL for their publicly accessible data repositories.

Conflicts of Interest: The authors declare no conflict of interest.

\section{References}

1. Solomon, S.; Qin, D.; Manning, M.; Chen, Z.; Marquis, M.; Averyt, K.B.; Tignor, M.; Miller, H.L. (Eds.) Climate Change 2007: The Physical Science Basis; Contribution of Working Group I to the Fourth Assessment Report of the Intergovernmental Panel on Climate Change; Cambridge University Press: Cambridge, UK; New York, NY, USA, 2007; p. 333.

2. Stocker, T.F.; Qin, D.; Plattner, G.-K.; Tignor, M.; Allen, S.K.; Boschung, J.; Nauels, A.; Xia, Y.; Bex, V.; Midgley, P.M. (Eds.) Climate Change 2013: The Physical Science Basis; Contribution of Working Group I to the Fifth Assessment Report of the Intergovernmental Panel on Climate Change; Cambridge University Press: Cambridge, UK; New York, NY, USA, 2013. [CrossRef]

3. Eyring, V.; Bony, S.; Meehl, G.A.; Senior, C.A.; Stevens, B.; Stouffer, R.J.; Taylor, K.E. Overview of the Coupled Model Intercomparison Project Phase 6 (CMIP6) experimental design and organization. Geosci. Model Dev. 2016, 9, 1937-1958. [CrossRef] 
4. Flato, G.; Marotzke, J.; Abiodun, B.; Braconnot, P.; Chou, S.C.; Collins, W.; Cox, P.; Driouech, F.; Emori, S.; Eyring, V.; et al. Evaluation of Climate Models. In Climate Change 2013: The Physical Science Basis; Stocker, T.F., Qin, D., Plattner, G.-K., Tignor, M., Allen, S.K., Boschung, J., Nauels, A., Xia, Y., Bex, V., Midgley, P.M., Eds.; Contribution of Working Group I to the Fifth Assessment Report of the Intergovernmental Panel on Climate Change; Cambridge University Press: Cambridge, UK; New York, NY, USA, 2013; pp. 741-866. [CrossRef]

5. Church, J.A.; Clark, P.U.; Cazenave, A.; Gregory, J.M.; Jevrejeva, S.; Levermann, A.; Merrifield, M.A.; Milne, G.A.; Nerem, R.S.; Nunn, P.D.; et al. Sea Level Change. In Climate Change 2013: The Physical Science Basis; Stocker, T.F., Qin, D., Plattner, G.-K., Tignor, M., Allen, S.K., Boschung, J., Nauels, A., Xia, Y., Bex, V., Midgley, P.M., Eds.; Contribution of Working Group I to the Fifth Assessment Report of the Intergovernmental Panel on Climate Change; Cambridge University Press: Cambridge, UK; New York, NY, USA, 2013; pp. 1137-1216. [CrossRef]

6. Integrated Climate Data Center (ICDC) Website for AR5 Sea Level Data. Available online: http:/ / icdc.cen. uni-hamburg.de/1/daten/ocean/ar5-slr.html (accessed on 8 April 2017).

7. IPCC. Press Release-IPCC Agrees Special Reports. AR6 workplan, 2016/03/PR, 14 April 2016. Available online: http://www.ipcc.ch/news_and_events/pdf/press/160414_pr_p43.pdf (accessed on 15 April 2017).

8. Slangen, A.B.A.; Carson, M.; Katsman, C.A.; van de Wal, R.S.W.; Köhl, A.; Vermeersen, L.L.A.; Stammer, D. Projecting twenty-first century regional sea-level changes. Clim. Chang. 2014, 124, 317-332. [CrossRef]

9. Slangen, A.A.; Meyssignac, B.; Agosta, C.; Champollion, N.; Church, J.A.; Fettweis, X.; Ligtenberg, S.R.M.; Marzeion, B.; Melet, A.; Palmer, M.D.; et al. Evaluating Model Simulations of Twentieth-Century Sea-Level Rise. Part I: Global Mean Sea-Level Change. J. Clim. 2017, 30, 8539-8563. [CrossRef]

10. Meyssignac, B.; Slangen, A.A.; Melet, A.; Church, J.A.; Fettweis, X.; Marzeion, B.; Agosta, C.; Ligtenberg, S.R.M.; Spada, G.; Richter, K.; et al. Evaluating Model Simulations of Twentieth-Century Sea-Level Rise. Part II: Regional Sea-Level Changes. J. Clim. 2017, 30, 8565-8593. [CrossRef]

11. Holgate, S.J.; Matthews, A.; Woodworth, P.L.; Rickards, L.J.; Tamisiea, M.E.; Bradshaw, E.; Foden, P.R.; Gordon, K.M.; Jevrejeva, S.; Pugh, J. New data systems and products at the permanent service for mean sea level. J. Coast. Res. 2012, 29, 493-504. [CrossRef]

12. Permanent Service for Mean Sea Level (PSMSL) Website. Available online: http://www.psmsl.org (accessed on 8 April 2017).

13. Hogarth, P. Preliminary analysis of acceleration of sea level rise through the twentieth century using extended tide gauge data sets (August 2014). J. Geophys. Res. Oceans 2014, 119, 7645-7659. [CrossRef]

14. AVISO Website. Available online: http:/ / www.aviso.altimetry.fr/duacs / (accessed on 10 June 2017).

15. Integrated Climate Data Center (ICDC) Website for AVISO SSH Data. Available online: http:/ /icdc.cen.unihamburg.de/1/daten/ocean/ssh-aviso.html (accessed on 10 June 2017).

16. Watson, P.J. Identifying the best performing time series analytics for sea-level research. In Time Series Analysis and Forecasting: Contributions to Statistics; Rojas, I., Pomares, H., Eds.; Springer International Publishing: Berlin, Switzerland, 2016; pp. 261-278. [CrossRef]

17. Alexandrov, T.; Bianconcini, S.; Dagum, E.B.; Maass, P.; McElroy, T.S. A review of some modern approaches to the problem of trend extraction. Econ. Rev. 2012, 31, 593-624. [CrossRef]

18. Golyandina, N.; Zhigljavsky, A. Singular Spectrum Analysis for Time Series; Springer Science \& Business Media: Berlin, Germany, 2013.

19. Golyandina, N.; Nekrutkin, V.; Zhigljavsky, A.A. Analysis of Time Series Structure: SSA and Related Techniques; Chapman and Hall/CRC Press: London, UK, 2001.

20. Alexandrov, T.; Golyandina, N. Automatic extraction and forecast of time series cyclic components within the framework of SSA. In Proceedings of the 5th St. Petersburg Workshop on Simulation, St. Petersburg, Russia, 26 June-2 July 2005; pp. 45-50.

21. Project for Statistical Computing Website. Available online: https://www.r-project.org/ (accessed on 8 April 2017).

22. Watson, P.J. Development of a unique synthetic data set to improve sea-level research and understanding. J. Coast. Res. 2015, 31, 758-770. [CrossRef]

23. Watson, P.J. How to improve estimates of real-time acceleration in the mean sea level signal. J. Coast. Res. 2016, 75, 780-784. [CrossRef]

24. Watson, P.J. Acceleration in US Mean Sea Level? A New Insight using Improved Tools. J. Coast. Res. 2016, 32, 1247-1261. [CrossRef] 
25. Watson, P.J. Acceleration in European Mean Sea Level? A New Insight Using Improved Tools. J. Coast. Res. 2017, 33, 23-38. [CrossRef]

26. Watson, P.J. Improved Techniques to Estimate Mean Sea Level, Velocity and Acceleration from Long Ocean Water Level Time Series to Augment Sea Level (and Climate Change) Research. Ph.D. Thesis, University of New South Wales, Sydney, Australia. under review, submitted for examination October 2017.

27. Kondrashov, D.; Ghil, M. Spatio-temporal filling of missing points in geophysical data sets. Nonlinear Process. Geophys. 2006, 13, 151-159. [CrossRef]

28. Stineman, R.W. A consistently well-behaved method of interpolation. Creat. Comput. 1980, 6, 54-57.

29. SONEL Website. Available online: http://www.sonel.org/spip.php?page=gps\&idStation=2722 (accessed on 8 April 2017).

30. Santamaría-Gómez, A.; Gravelle, M.; Collilieux, X.; Guichard, M.; Míguez, B.M.; Tiphaneau, P.; Wöppelmann, G. Mitigating the effects of vertical land motion in tide gauge records using a state-of-the-art GPS velocity field. Glob. Planet. Chang. 2012, 98, 6-17. [CrossRef]

31. Ostanciaux, É.; Husson, L.; Choblet, G.; Robin, C.; Pedoja, K. Present-day trends of vertical ground motion along the coast lines. Earth-Sci. Rev. 2012, 110, 74-92. [CrossRef]

32. Pfeffer, J.; Allemand, P. The key role of vertical land motions in coastal sea level variations: A global synthesis of multisatellite altimetry, tide gauge data and GPS measurements. Earth Planet. Sci. Lett. 2016, 439, $39-47$. [CrossRef]

33. Peltier, W.R. Global glacial isostasy and the surface of the ice-age Earth: The ICE-5G (VM2) model and GRACE. Annu. Rev. Earth Planet. Sci. 2004, 32, 111-149. [CrossRef]

34. Lambeck, K.; Smither, C.; Johnston, P. Sea-level change, glacial rebound and mantle viscosity for northern Europe. Geophys. J. Int. 1998, 134, 102-144. [CrossRef]

35. O’Dea, A.; Lessios, H.A.; Coates, A.G.; Eytan, R.I.; Restrepo-Moreno, S.A.; Cione, A.L.; Collins, L.S.; de Queiroz, A.; Farris, D.W.; Norris, R.D.; et al. Formation of the Isthmus of Panama. Sci. Adv. 2016, 2, e1600883. [CrossRef] [PubMed]

36. Phien-Wej, N.; Giao, P.H.; Nutalaya, P. Land subsidence in Bangkok, Thailand. Eng. Geol. 2006, 82, $187-201$. [CrossRef]

37. Fasullo, J.T.; Nerem, R.S.; Hamlington, B. Is the detection of accelerated sea level rise imminent? Sci. Rep. 2016, 6. [CrossRef]

38. Minobe, S. Resonance in bidecadal and pentadecadal climate oscillations over the North Pacific: Role in climatic regime shifts. Geophys. Res. Lett. 1999, 26, 855-858. [CrossRef]

39. Sturges, W.; Douglas, B.C. Wind effects on estimates of sea level rise. J. Geophys. Res. Oceans $2011,116$. [CrossRef]

40. Qiu, B.; Chen, S. Multidecadal sea level and gyre circulation variability in the northwestern tropical Pacific Ocean. J. Phys. Oceanogr. 2012, 42, 193-206. [CrossRef]

41. Chambers, D.P.; Merrifield, M.A.; Nerem, R.S. Is there a 60-year oscillation in global mean sea level? Geophys. Res. Oceans 2012, 39, 39. [CrossRef]

42. Calafat, F.; Chambers, D. Quantifying recent acceleration in sea level unrelated to internal climate variability. Geophys. Res. Lett. 2013, 40, 3661-3666. [CrossRef]

43. Houston, J.R.; Dean, R.G. Effects of sea-level decadal variability on acceleration and trend difference. J. Coast. Res. 2013, 29, 1062-1072. [CrossRef]

44. Richter-Menge, J.; Overland, J.E.; Mathis, J.T. (Eds.) Arctic Report Card. 2016. Available online: http: / / www.arctic.noaa.gov/Report-Card (accessed on 25 May 2017).

45. Provisional World Meteorological Organization Statement on the Status of the Global Climate in 2016. Press Release No. 15, Published 14 November 2016. Available online: https:/ / public.wmo.int/en/media/pressrelease/ provisional-wmo-statement-status-of-global-climate-2016 (accessed on 6 May 2017).

46. IOC-UNESCO and UNEP. Open Ocean: Status and Trends, Summary for Policy Makers; United Nations Environment Programme (UNEP): Nairobi, Kenya, 2016.

47. Bolch, T.; Kulkarni, A.; Kääb, A.; Huggel, C.; Paul, F.; Cogley, J.G.; Frey, H.; Kargel, J.S.; Fujita, K.; Scheel, M.; et al. The state and fate of Himalayan glaciers. Science 2012, 336, 310-314. [CrossRef] [PubMed]

48. Wuebbles, D.J.; Fahey, D.W.; Hibbard, K.A.; Dokken, D.J.; Stewart, B.C.; Maycock, T.K. (Eds.) Climate Science Special Report: Fourth National Climate Assessment; U.S. Global Change Research Program: Washington, DC, USA, 2017. 
49. Neumann, B.; Vafeidis, A.T.; Zimmermann, J.; Nicholls, R.J. Future coastal population growth and exposure to sea-level rise and coastal flooding-a global assessment. PLOS ONE 2015, 10, e0118571. [CrossRef] [PubMed]

50. Watkiss, P. The ClimateCost Project. Final Report, Volume 1: Europe; Stockholm Environmental Institute: Stockholm, Sweden, 2011; ISBN 978-91-86125-35-6. 